\title{
Bronchodilatory effects of ipratropium bromide in patients with tetraplegia
}

\author{
PL Almenoff ${ }^{1,3,5}$, LR Alexander ${ }^{3}$, AM Spungen $^{1-3}$, MD Lesser $^{1,5}$ and WA Bauman ${ }^{1-4}$ \\ Departments of ${ }^{1}$ Medicine and ${ }^{2}$ Rehabilitation Medicine, Mount Sinai School of Medicine, New York; ${ }^{3}$ Spinal \\ Cord Damage Research Center, ${ }^{4}$ Spinal Cord Injury Service and ${ }^{5}$ Pulmonary/Critical Care Medicine, Veterans \\ Affairs Medical Center, Bronx, New York, USA
}

\begin{abstract}
Airway hyperresponsiveness was recently described in patients with chronic cervical spinal cord injury (tetraplegia). The response was attributed to unopposed cholinergic bronchoconstrictor activity due to loss of sympathetic innervation of the airway. To determine if the administration of a cholinergic antagonist alters resting airway tone in these patients, ipratropium bromide $(72 \mu \mathrm{g})$ was administered by aerosol to 25 tetraplegic patients. We found that 12 of 25 patients $(48 \%)$ had significant improvement (defined as $\geqslant 12 \%$ ) in forced expired volume in $1 \mathrm{~s}\left(\mathrm{FEV}_{1}\right)$ and/or forced vital capacity (FVC). A significant correlation between airway responsiveness and complaints of dyspnea at rest, completeness of injury (sensory), or smoking history was not found. These findings of improved airflow after the use of an anticholinergic bronchodilator agent provides further evidence that transection of the cervical cord results in unopposed parasympathetic activity and a resultant increase in resting airway tone.
\end{abstract}

Keywords: bronchial obstruction; pulmonary; lungs; spinal cord injury; tetraplegia; anti-cholinergic agents; ipratropium

\section{Introduction}

It was recently reported that approximately $40 \%$ of otherwise healthy patients with tetraplegia undergoing routine pulmonary function testing had a significant bronchodilator response $(>12 \%)$ following inhalation of a beta ${ }_{2}$ agonist. ${ }^{1}$ This finding suggested that many patients with cervical spinal cord injury have an obstructive ventilatory impairment, characterized by an increase in resting airway tone, in addition to the well described restrictive ventilatory defect. ${ }^{2-8}$ Further evidence of ventilatory impairment comes from methacholine challenge testing, which demonstrated marked airway hyperresponsiveness in all patients with tetraplegia, a response which was completely blocked by pretreatment with the cholinergic antagonist ipratropium bromide. ${ }^{9}$

Based upon these findings, it was postulated that airway hyperresponsiveness in patients with tetraplegia represents a loss of modulatory sympathetic fibers, which originate in the upper six thoracic segments of the spinal cord; thus, broncho-constrictive cholinergic innervation, which arises in the vagal nuclei of the brainstem and passes down the vagus nerves to synapse in ganglia that are located in the walls of airway, would remain intact. ${ }^{10}$

To further evaluate the apparent cholinergic hyperresponsiveness in patients with tetraplegia we assessed pulmonary function parameters before and after the administration of ipratropium bromide to determine if the agent caused bronchodilation in this population.

\section{Methods}

Twenty-five male patients with tetraplegia were recruited from the Spinal Cord Injury Service at the Veterans Affairs Medical Center, Bronx, New York. The study group consisted of 10 current smokers and 15 non-smokers (defined as those who are ex-smokers with no cigarette use for 1 year or more, or a lifetime never smoker). Six patients had complete motor and sensory loss, 17 had complete motor and incomplete sensory loss, and two had incomplete motor and sensory loss. At the time of study, no subject displayed evidence of respiratory tract infections or other acute pulmonary symptoms, and none gave a history of asthma or allergies.

Pulmonary function testing was performed with the patients seated upright in their wheelchairs using a SensorMedics dry rolling seal spirometer (Yorba Linda, CA). Spirometry was performed before and $45 \mathrm{~min}$ after inhalation via a spacer (Inspirease, Schering, Kenilworth, NJ) of four puffs ( $72 \mu \mathrm{g})$ of ipratropium bromide (Boehringer Ingelheim, Ridgefield, CT). American Thoracic Society (ATS) guidelines for spirometry were followed with reproducibility for FVC, $\mathrm{FEV}_{1}$, volume of extrapolation, and end of test criteria (no flow for $2 \mathrm{~s}$ and exhalation for $\geqslant 6 \mathrm{~s}$ ) being achieved. ${ }^{11}$ Those patients classified as 'responders' achieved a bronchodilator response as described by the ATS $(\geqslant 12 \%$ increase post bronchodilator for FVC and/or $\left.\mathrm{FEV}_{1}\right) .{ }^{12}$ Those with less than a $12 \%$ improvement were classified as 'non-responders'. All patients 
were able to complete pre- and post-bronchodilator testing. The spirometric standards of Morris were used. ${ }^{13}$ This study was approved by the institutional review board of the Veterans Affairs Medical Center.

The results are reported as mean \pm SEM. A paired $t$ test was performed between the pre- and postspirometry values for the study group as a whole. $\chi^{2}$ analysis was used to determine differences in the frequency of responders versus non-responders for dyspnea (yes, no), completeness of injury (incomplete sensory, complete sensory), and smoking history (current smokers, non-smokers).

\section{Results}

Characteristics of the study population including age, duration of injury, and smoking history are shown (Table 1). Overall, 12 of 25 patients (48\%) had a positive bronchodilator response. For the study group as a whole, the average $\mathrm{FEV}_{1}$ and FVC were significantly $(P=0.0036$ and $P=0.0084$, respectively) higher post-bronchodilator than pre-bronchodilator. Spirometry parameters for the responder and nonresponder groups before and after administration of ipratropium bromide for current smokers and nonsmokers are shown (Table 2). In the smoking history subgroups, a significant bronchodilator response was seen in six of $10(60 \%)$ current smokers and six of 15 $(40 \%)$ non-smokers. $\chi^{2}$ analyses revealed no significant differences between the number of patients with dyspnea at rest, smoking history, or completeness of cord lesion, and the bronchodilator response to ipratropium bromide (Table 3).

\section{Discussion}

In this study, we found that approximately $50 \%$ of patients with tetraplegia had a positive bronchodilator response to $72 \mu \mathrm{g}$ of inhaled ipratropium bromide. The

Table 1 Characteristics of the patients

\begin{tabular}{lc}
\hline Age $(\mathrm{y})$ & $43 \pm 3$ \\
Height $(\mathrm{cm})$ & $69.7 \pm 0.6$ \\
DOI (y) & $11 \pm 2$ \\
Incomplete & $19(76 \%)$ \\
Complete & $6(24 \%)$ \\
Dyspnea at rest & \\
$\quad$ Yes & $7(28 \%)$ \\
$\quad$ No & $18(72 \%)$ \\
Smoking history & \\
$\quad$ Non-smoker & \\
Current smoker & $15(60 \%)$ \\
\hline
\end{tabular}

Results are reported in mean $\pm S E M$ where $\mathrm{DOI}=$ duration of injury in years $(y)$; non-smoker = lifetime neversmokers or ex-smoker who has quit smoking $>1$ year; current smoker $=$ those who currently smoke or have quit for $\leqslant 1$ year number of responders far exceeds that found in studies of normal patients, which demonstrated no change in parameters of static lung volumes when $240 \mu \mathrm{g}$ were inhaled. ${ }^{14}$ Our current findings, when viewed in the context of our previous observation that 14 of 34 (41\%) tetraplegic patients had significant bronchodilatation following inhalation of nebulized metaproterenol sulfate $(15 \mathrm{mg}),{ }^{1}$ provide additional support that resting airway tone is increased in patients with tetraplegia. Although the results of the two studies were essentially the same, one difference was that the beta ${ }_{2}$ agonist (metaproterenol) was given by a powered nebulizer (50 psi), whereas the anticholinergic (ipratropium bromide) was given via a spacer device. In addition, the previous finding that eight of eight non-smoking patients with tetraplegia were hyperresponsive to inhaled methacholine ${ }^{9}$ demonstrated that airway hyperreactivity is also present.

A likely explanation for our previous findings ${ }^{1,9}$ is that transection of the cervical spinal cord disrupts sympathetic innervation of the lung, which originates in the upper six thoracic segments, thereby leaving intact parasympathetic (cholinergic) nerves, which arise in vagal nuclei in the brainstem and pass down the vagus nerve to synapse in ganglia situated in airway walls. ${ }^{0,15}$ As a result, cholinergic bronchoconstrictor activity is unopposed by bronchodilatory sympathetic fibers, which presumably interact with parasympathetic ganglia cells in the peribronchial plexa to modulate transmission of post-ganglionic parasympathetic fibers. ${ }^{15}$ Support comes from studies involving dogs and guinea pigs, which have shown that stimulation of thoracic sympathetic nerves causes bronchodilation that is abolished by beta-antagonist and unaffected by adrenalectomy. ${ }^{16,17}$ Also, of more direct relevance to spinal cord injury, in guinea pigs it has been observed that electrical stimulation of structures within the rostral region of the dorsal medulla activates a sympathetic inhibitory pathway. ${ }^{18,19}$ Injection of lidocaine into the spinal cord at the level of $C_{1}-C_{2}$ to eliminate bulbospinal sympathetic neurotransmission, or surgical section of the cord at this location, potentiated CNS-induced bronchospasm. ${ }^{18,19}$

The use of anticholinergic agents to treat diseases of the airway is based on their ability to compete with acetylcholine at muscarinic receptor sites. ${ }^{20}$ These receptors have been demonstrated on airway smooth muscle cells and mucous cells, especially in submucosal glands. In human airways, different muscarinic subtypes have been identified, which include $M_{1}$ receptors on sympathetic nerves and parasympathetic ganglia, $M_{2}$ receptors on cholinergic nerves (these receptors function as feedback inhibitory receptors), and $M_{3}$ receptors on airway smooth muscle. Since acetylcholine released from post-ganglionic parasympathetic nerve endings has been shown to contract smooth muscle, ${ }^{15}$ antimuscarinic drugs act to reduce vagally mediated increases in bronchomotor tone.

Our findings suggest that patients with tetraplegia may demonstrate physiological improvement in pulmonary function with the use of a beta ${ }_{2}$ agonist or an 
Table 2 Results of pre- and post-bronchodilator response

\begin{tabular}{|c|c|c|c|c|c|c|}
\hline \multirow[t]{2}{*}{ Parameter } & \multicolumn{2}{|c|}{ Pre } & \multicolumn{4}{|c|}{ Post } \\
\hline & $\begin{array}{c}R \\
(n=6)\end{array}$ & $\begin{array}{c}N R \\
(n=4)\end{array}$ & $\begin{array}{c}R \\
(n=6)\end{array}$ & $\begin{array}{c}R \\
\% C h\end{array}$ & $\begin{array}{c}N R \\
(n=4) .\end{array}$ & $\begin{array}{c}N R \\
\% C h\end{array}$ \\
\hline \multicolumn{7}{|l|}{ Current smokers } \\
\hline FVC (1) & $2.30 \pm 0.15$ & $2.68 \pm 0.19$ & $2.54 \pm 0.08$ & & $2.60 \pm 0.18$ & \\
\hline FVC (\%) & $48 \pm 2$ & $57 \pm 7$ & $54 \pm 3$ & $12 \pm 5$ & $55 \pm 5$ & $-2 \pm 6$ \\
\hline $\mathrm{FEV}_{1}(\mathrm{l})$ & $1.72 \pm 0.25$ & $2.36 \pm 0.19$ & $2.00 \pm 0.28$ & & $2.29 \pm 0.18$ & \\
\hline $\mathrm{FEV}_{1}(\%)$ & $46 \pm 5$ & $64 \pm 8$ & $54 \pm 6$ & $17 \pm 2$ & $63 \pm 6$ & $-2 \pm 6$ \\
\hline $\mathrm{FEV}_{1} / \mathrm{FVC}$ & $74 \pm 8$ & $89 \pm 5$ & $82 \pm 6$ & & $88 \pm 3$ & \\
\hline $\mathrm{FEF}_{25-75}\left(1 \mathrm{~s}^{-1}\right)$ & $1.62 \pm 0.43$ & $3.08 \pm 0.51$ & $2.44 \pm 0.63$ & & $2.96 \pm 0.41$ & \\
\hline $\mathrm{FEF}_{25-75}(\%)$ & $40 \pm 10$ & $77 \pm 12$ & $40 \pm 10$ & $54 \pm 7$ & $76 \pm 7$ & $<1 \pm 12$ \\
\hline \multicolumn{7}{|l|}{ Non-smokers } \\
\hline FVC (1) & $2.23 \pm 0.10$ & $2.64 \pm 0.26$ & $2.57 \pm 0.12$ & & $2.69 \pm 0.25$ & \\
\hline FVC (\%) & $46 \pm 2$ & $50 \pm 5$ & $53 \pm 3$ & $16 \pm 4$ & $51 \pm 5$ & $2 \pm 1$ \\
\hline $\mathrm{FEV}_{1}(\mathrm{l})$ & $1.85 \pm 0.19$ & $2.31 \pm 0.18$ & $2.11 \pm 0.20$ & & $2.33 \pm 0.18$ & \\
\hline $\mathrm{FEV}_{1}(\%)$ & $50 \pm 5$ & $59 \pm 5$ & $58 \pm 5$ & $15 \pm 3$ & $60 \pm 5$ & $1 \pm 1$ \\
\hline $\mathrm{FEV}_{1} / \mathrm{FVC}$ & $82 \pm 5$ & $89 \pm 3$ & $82 \pm 6$ & & $88 \pm 3$ & \\
\hline $\mathrm{FEF}_{25-75}\left(1 \mathrm{~s}^{-1}\right)$ & $2.23 \pm 0.51$ & $3.07 \pm 0.27$ & $2.42 \pm 0.57$ & & $3.20 \pm 0.32$ & \\
\hline $\mathrm{FEF}_{25-75}(\%)$ & $59 \pm 14$ & $82 \pm 11$ & $63 \pm 15$ & $12 \pm 14$ & $85 \pm 11$ & $6 \pm 7$ \\
\hline
\end{tabular}

The results are reported as mean $\pm S E M$ where $F V C=$ forced vital capacity, $F E V_{1}=$ forced expired volume in $1 \mathrm{~s}$, $\mathrm{FEF}_{25-75}=$ forced expiratory flow rate (l pers) between 25 and $75 \%$ of the exhaled volume and $\mathrm{R}=$ responders $\geqslant 12 \%$ post-bronchodilator, $\mathrm{NR}=$ non-responders. Pre $=$ pre bronchodilator, post $=$ post bronchodilator, $\% \mathrm{Ch}=$ percent change post-bronchodilator spirometry results.

Table 3 Observed frequency of dyspnea, cord lesion completeness, and smoking history for responders $(\geqslant 12 \%$ post bronchodilator) and non-responders

\begin{tabular}{lrc}
\hline & Responders & Non-responders \\
\hline Dyspnea & $3(43 \%)$ & 4 \\
$\quad$ Yes & $9(50 \%)$ & 9 \\
No & $10(53 \%)$ & 9 \\
Cord Lesion & $2(33 \%)$ & 4 \\
$\quad$ Incomplete & & \\
$\quad$ Complete & $6(40 \%)$ & 4 \\
Smoker & $6(60 \%)$ & 9 \\
$\quad$ Yes & \\
No &
\end{tabular}

anticholinergic agent. Although no detailed studies have been performed which evaluate the respiratory symptoms among patients with high spinal cord injury, in one survey, it was reported that $18 \%$ (seven of 39 ) with complete lesions complained of chronic cough, $18 \%$ (seven of 39 ) of chronic sputum production, $24 \%$ (nine of 37) of persistent wheeze, and 50\% (19 of 38) of any wheeze. ${ }^{21}$ Also, since atelectasis and pneumonia are the major causes of morbidity and mortality in patients with spinal cord injury, ${ }^{22-25}$ it is conceivable that chronic inhalation of a beta ${ }_{2}$ agonist or anticholinergic agent may decrease the incidence of mucus retention and respiratory complications. A long term study would be required to determine if chronic use of bronchodilators benefits patients with spinal cord injury.

\section{References}

1 Spungen AM, Dicpinigaitis PV, Almenoff PL, Bauman WA. Pulmonary obstruction in individuals with cervical spinal cord lesions unmasked by bronchodilator administration. Paraplegia 1993; 31: 404-407.

2 Hemingway A, Bors E, Hobby RP. An investigation of the pulmonary function of paraplegics. J Clin Invest 1958; 37 773-782

3 Anke A, Aksnes AK, Stanghelle JK, Hjeltnes N. Lung volumes in tetraplegic patients according to cervical spinal cord injury level. Scand J Rehabil Med 1993; 25: 73-77.

4 Forner JV. Lung volumes and mechanics of breathing in tetraplegics. Paraplegia 1980; 8: 258-266.

$5 \mathrm{Fugl}$-Meyer AR. Effects of respiratory muscle paralysis in tetraplegic and paraplegic patients. Scand J Rehabil Med 1971; 3: $141-150$.

6 Stone DJ, Keltz H. The effect of respiratory muscle dysfunction on pulmonary function. Am Rev Resp Dis 1963; 88: 621-629.

7 Bergofsky EH. Mechanism for respiratory insufficiency after cervical cord injury. Ann Intern Med 1964; 61: 435-447.

8 Ohry A, Molho M, Rozin R. Alterations of pulmonary function in spinal cord injured patients. Paraplegia 1975; 13: 101-108.

9 Dicpinigaitis PV et al. Bronchial hyperresponsiveness after cervical spinal cord injury. Chest 1994; 105: 1073-1076.

10 Barnes PJ. Neural control of human airways in health and disease. Am Rev Respir Dis 1986; 134: 1289-1314.

11 American Thoracic Society. Standard of spirometry: 1987 update. Am Rev Respir Dis 1987; 136: 1285-1298.

12 American Thoracic Society. Lung function testing: selection of reference values and interpretative strategies. Am Rev Respir Dis 1991; 144: 1202-1218.

13 Morris JF, Koski A, Johnson LC. Spirometric standards for healthy nonsmoking adults. Am Rev Respir Dis 1971; 103 57-67.

14 DeTroyer A, Yernault JC, Rodenstein D. Effects of vagal blockade on lung mechanics in normal man. J Appl Physiol 1979; 46: 217-226.

15 Gross NJ, Skorodik MS. Anticholinergic, antimuscarinic bronchodilators. Am Rev Respir Dis 1984; 129: 856-870.

16 Cabezas GA, Graf PD, Nadel JA. Sympathetic versus para- 
sympathetic nervous regulation of airways in dogs. $J$ Appl Physiol 1971; 31: 651-655.

17 Ainsworth GA, Garland LG, Payne AN. Modulation of bronchoconstrictor responses to histamine in purebred guineapigs by sympathetic nerve stimulation. $\mathrm{Br} J$ Pharmacol 1981; 77: $249-754$

18 Hey JA, Del Prado M, Chapman RW. Activation of a novel medullary pathway elicits a vagal, cholinergic bronchoconstriction in guinea-pigs. Pulm Pharmacol 1990; 3: 53-54.

19 Hey JA, Del Prado M, Chapman RW. Central nervous system control of bronchomotor tone: pharmacological characterization of parasympathetic constrictor and sympathetic inhibitory responses in guinea-pigs. J Auton Pharmacol 1993; 13: 341-350.

20 Barnes PJ. Muscarinic receptor subtypes: implications for lung disease. Thorax 1989; 44: 161-167.

21 Ashba $\mathrm{J}$ et al. Spirometry-acceptability and reproducibility in spinal cord injured subjects. J Am Paraplegia Soc 1993; 16: 197-203.

22 Fishburn MJ, Marino RJ, Ditunno JF. Atelectasis and pneumonia in acute spinal cord injury. Arch Phys Med Rehabil 1990; 71: $197-200$

23 Reines HD, Harris RC. Pulmonary complications of acute spinal cord injuries. Neurosurgery 1987; 21: 193-196.

24 Polatty RC, McElaney MA, Marcelino V. Pulmonary complications in the spinal cord injury patient. Phys Med Rehabil 1987; 1: $353-373$.

25 DeVivo MJ et al. Cause of death for patients with spinal cord injuries. Arch Intern Med 1989; 149: 1761-1766. 